\title{
Thermal anomaly in sodium potassium sulphate crystals
}

\author{
M. E. Kassem, S. H. Kandil, E. F. El-Wahidy and M. El-Gamal \\ Institute of Post Graduate Studies and Research (UNARC), \\ University of Alexandria, Alexandria, Egypt
}

(Reçu le 8 novembre 1983, révisé le 20 février 1984, accepté le 14 mars 1984)

\begin{abstract}
Résumé. - Les propriétés thermales du $\mathrm{NaKSO}_{4}$ cristal, que l'on a fait croître à $315 \mathrm{~K}$ par la méthode d'évaporation lente, ont été étudiées dans l'intervalle de température entre 300 et $500 \mathrm{~K}$ en faisant des mesures de thermomécanique (TMA), de thermogravimétrie (TG), d'analyse thermale différentielle (DTA), et d'examen de calorimétrie différentielle (DSC). Les coefficients d'expansion thermale dans les trois directions cristallographiques fondamentales ont montré un comportement anormal près de $453 \mathrm{~K}$. Aussi, près de cette température, des effets anisotropes ont été observés et pas de perte de poids n'a été détectée. Les mesures (DSC) de la chaleur spécifique à pression constante $C_{\mathrm{p}}$, ont montré un accroissement faible et continu durant l'accroissement de température plus un sommet à $453 \mathrm{~K}$.

Abstract. - The thermal properties of $\mathrm{NaKSO}_{4}$ crystal, grown at $315 \mathrm{~K}$ by the slow evaporation method, were studied in the $300-500 \mathrm{~K}$ temperature range by performing Thermomechanical (TMA), Thermogravimetry (TG), Differential Thermal Analysis (DTA) and Differential Scanning Calorimetry (DSC) measurements. Thermal expansion coefficients for the three fundamental crystallographic directions showed anomalous behaviour around $453 \mathrm{~K}$. Also, in this temperature range, anisotropic effects were observed and a weight loss was not detected. The DSC measurements of the specific heat at constant pressure $C_{\mathrm{p}}$, showed a slight continuous increase with increasing temperature and a peak at $453 \mathrm{~K}$.
\end{abstract}

\section{Introduction.}

The growing interest in the physical properties of double sulphate crystals is due to the fact that they show anomalous behaviour at transition points [1-5].

Sodium potassium sulphate is a member of the family of crystals having the general formula $\mathbf{M}^{\prime} \mathbf{M}^{\prime \prime} \mathbf{B X}_{4}$ (where $\mathrm{M}^{\mathrm{l}}$ stands for $\mathrm{Na}$ or $\mathrm{Li}, \mathrm{M}^{\mathrm{II}}$ stands for $\mathrm{K}, \mathrm{Na}$, $\mathrm{Rb}, \mathrm{Cs}$, ammonium $\left(\mathrm{NH}_{4}\right)$ or hydrazine $\left(\mathrm{N}_{2} \mathrm{H}_{5}\right)$ and $\mathrm{BX}_{4}$ stands for $\mathrm{SO}_{4}^{--}$or $\mathrm{SeO}_{4}^{--}$).

It is known that $\mathrm{NaKSO}_{4}$ crystals have orthorhombic symmetry at $300 \mathrm{~K}$ and belong to the $\mathrm{mmm}$ point group [6]. Moreover, pyroelectric and piezoelectric measurements on $\mathrm{NaKSO}_{4}$ crystals show that they have a centre of symmetry. The lack of information concerning the thermal behaviour of $\mathrm{NaKSO}_{4}$ stimulated the study for their physical properties.

\section{Crystal preparation and experimental techniques.}

Single crystals of sodium potassium sulphate $\mathrm{NaKSO}_{4}$ were grown from an aqueous solution of equimolar mixture of $\mathrm{Na}_{2} \mathrm{SO}_{4}$ and $\mathrm{K}_{2} \mathrm{SO}_{4}$ by the slow evapo- ration method at $315 \mathrm{~K}$. Purification of the crystals were achieved by slow recrystallization for five times. The crystals were cut along the three fundamental crystallographic axes using a wet thread saw and the samples prepared in the form of thin rectangular rods with the dimension of $3 \times 3 \times 20 \mathrm{~mm}^{3}$. The longest dimensions were oriented along the principal crystallographic directions [100], [010], [001].

The thermal behaviour of these crystals was studied in the temperature region between $300-500 \mathrm{~K}$ using the following techniques :

a) Thermomechanical analysis was performed with Heraeus TMA 500 dilatometer, fitted with a low temperature furnace. The sample temperature was monitored with $\mathrm{Ni}-\mathrm{Cr}-\mathrm{Ni}$ thermocouple inserted in a sample holder of the standard design. The linear thermal expansion coefficient was computed using the assumption that the quartz expansion coefficient was insignificant. The heating rate was $2 \mathrm{~K} / \mathrm{min}$.

b) Thermogravimetric measurements were performed with a Heraeus TGA 500 thermo-balance using a Pt-Rh-Pt temperature sensor. The $60 \mathrm{mg}$ samples were placed in a platinum crucible. The 
heating rate was $10 \mathrm{~K} / \mathrm{min}$. Dry nitrogen flowed over the samples at a rate of $15 \mathrm{ml} / \mathrm{min}$ and the chamber cooling water flow rate was $10 \mathrm{l} /$ hour.

c) Differential thermal analysis DTA was performed with a Heraeus DTA 500 analyser using a $\mathrm{Ni}-\mathrm{Cr}-\mathrm{Ni}$ temperature sensor. The $45 \mathrm{mg}$ sample was contained in a glass tube in the DTA cell. A heating rate of $5 \mathrm{~K} / \mathrm{min}$ was used.

d) The specific heat was determined by differential scanning calorimetric measurements using the base line method [7]. Lidded pans, made of aluminium, were used to eliminate base line sloping. A Pt 100 thermocouple was used as a temperature sensor. A $43 \mathrm{mg}$ sample was used and the heating rate was $5 \mathrm{~K} / \mathrm{min}$.

\section{Results and discussion.}

The thermal expansion coefficients were calculated from dilatometric measurements. The measurements were carried out when the temperature was increasing and once more when the temperature was decreasing and no hysterises phenomena were detected. Table I

\section{Table I.}

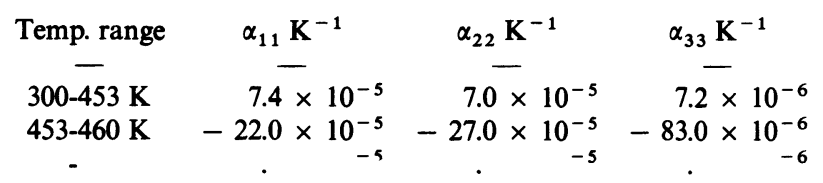

shows the average values of the linear expansion coefficients $\alpha_{i i}$ in different temperature ranges. Figure 1 (a, b and c) revealed, for the first time, that $\mathrm{NaKSO}_{4}$

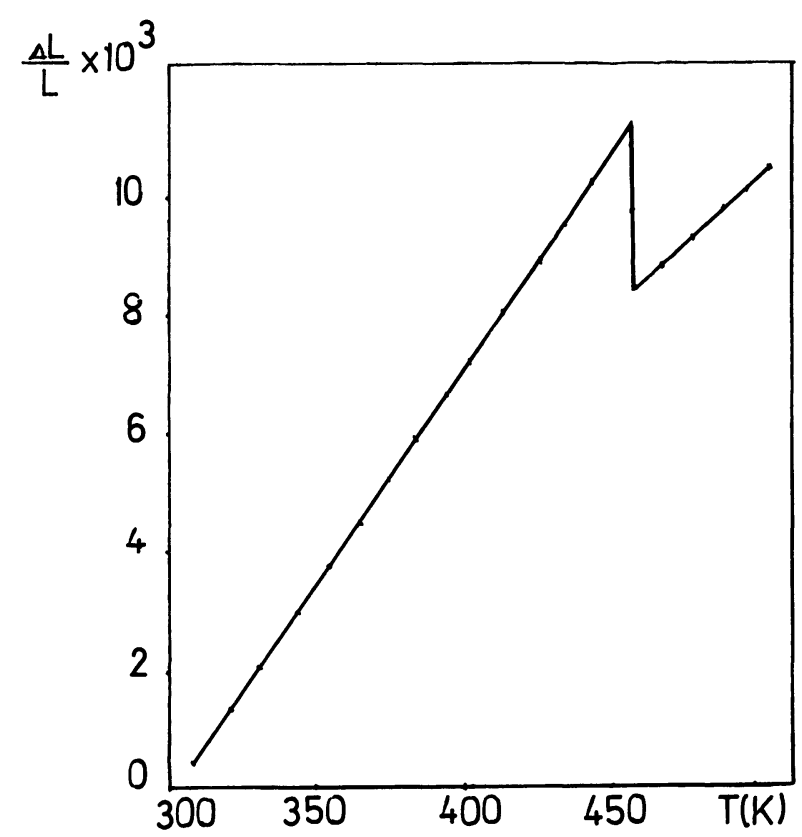

Fig. 1a. - Relative change of length measured along the $X$-axis of $\mathrm{NaKSO}_{4}$ crystal with temperature.

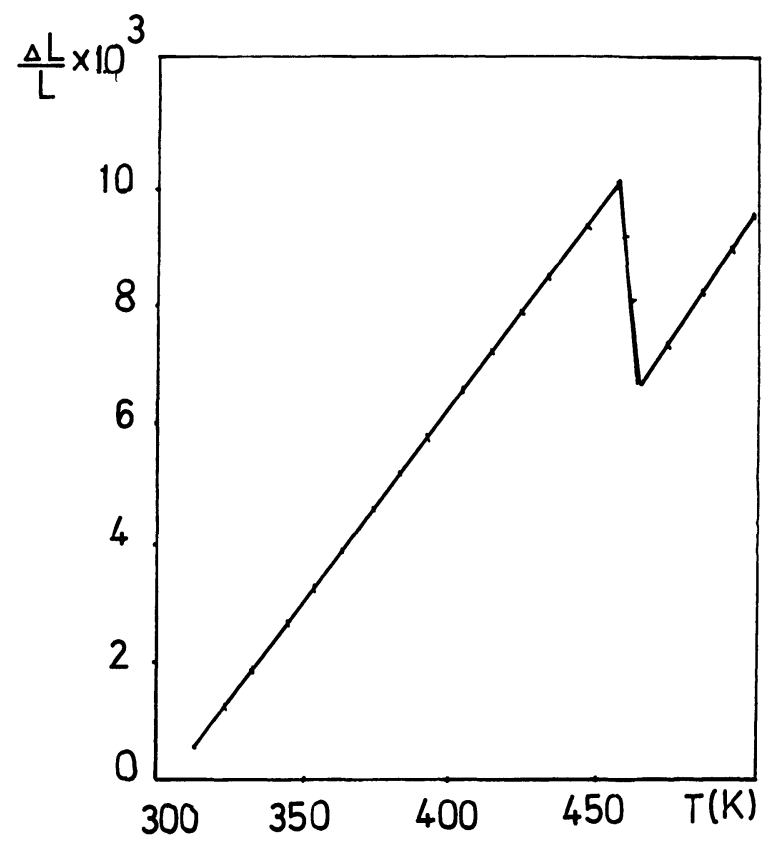

Fig. 1b. - Relative change of length measured along the $Y$-axis of $\mathrm{NaKSO}_{4}$ crystal with temperature.<smiles>C[AsH2][Mg]</smiles>

10

7.5

5

2.5

0

.2 .5

$-5$ $300 \quad 350 \quad 400 \quad 450 \quad T(K)$

Fig. 1c. - Relative change of length measured along the $Z$-axis of $\mathrm{NaKSO}_{4}$ crystal with temperature. 
exhibits major thermal expansion anomalies in the immediate vicinity of the temperature $453 \mathrm{~K}$. The thermal expansion is strongly anisotropic as shown by the large differences in contraction observed at temperatures above $T_{\mathrm{c}}=453 \mathrm{~K}$. The overall expansion is positive in the entire temperature region measured for the $X$ - and $Y$-directions and is negative in parts of the $453-500 \mathrm{~K}$ phase transition region in the $Z$-direction. The expansion is linear with positive slope below $453 \mathrm{~K}$, linear with a different negative slope between $453-460 \mathrm{~K}$ and linear with a different positive slope above $460 \mathrm{~K}$. The sudden change in the thermal expansion coefficients may be due to a second order lambda transformation.

The DTA measurements showed transition peaks in the temperature region $453-470 \mathrm{~K}$, as illustrated in figure $2 a$. The thermogravimetric curve, figure $2 b$, indicates that the sample did not lose weight in the entire temperature range of interest $300-500 \mathrm{~K}$.

The DSC measurements of the specific heat at constant pressure $C_{\mathrm{p}}$, figure 3 , showed a pronounced maximum at $T_{\mathrm{c}}=453 \mathrm{~K}$. This may indicate that

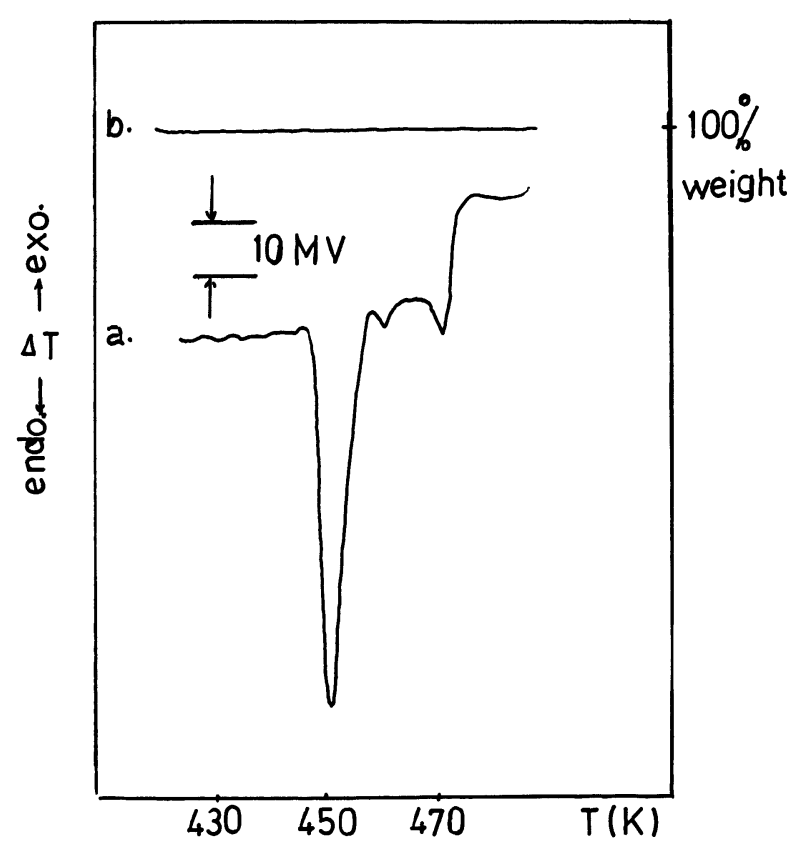

Fig. 2. - Thermal analysis curve for $\mathrm{NaKSO}_{4}$ crystal. a) DTA curve; b) TG curve.

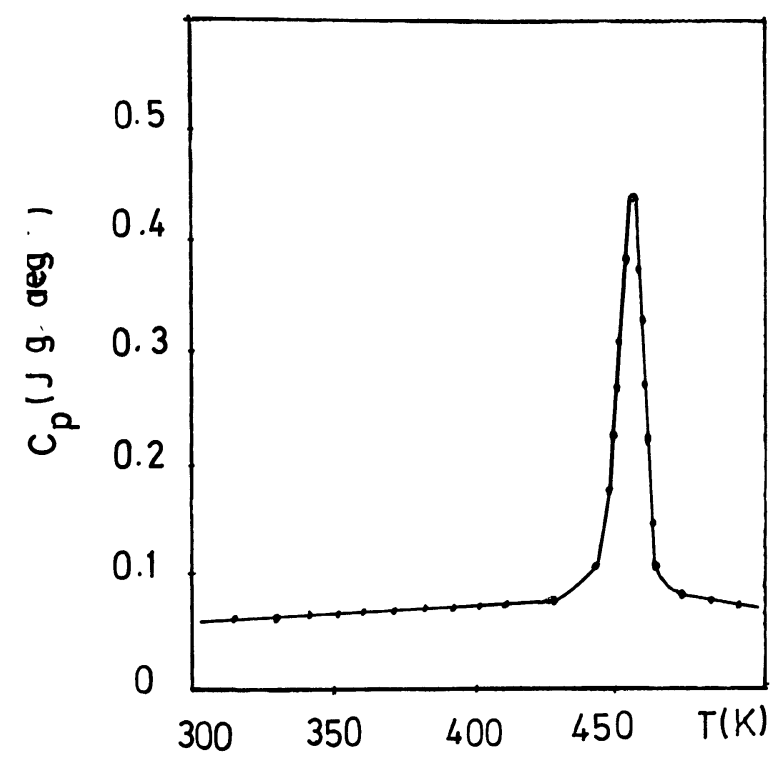

Fig. 3. - Temperature dependence of specific heat at constant pressure $C_{\mathrm{p}}$ for $\mathrm{NaKSO}_{4}$ crystal.

the entropy change is continuous and therefore there is no latent heat. However, since specific heat peak was observed (anomalous specific heat) and have the shape given by figure 3 , it could correspond to a second order lambda transition [8].

The anomalous behaviour of the thermal expansion coefficients, specific heat, and differential thermal analysis observed during the study of $\mathrm{NaKSO}_{4}$ crystals through the temperature range $300-500 \mathrm{~K}$ suggests that the crystal may present a structural phase transition at $T_{\mathrm{c}}=453 \mathrm{~K}$. This transition is probably from orthorhombic symmetry with point group $\mathrm{mmm}$ to monoclinic symmetry with point group $2 / \mathrm{m}$.

However, further and detailed investigation is still needed for such type of crystals to throw more light on its anomalous behaviour.

\section{Acknowledgments.}

The authors acknowledge the stimulated discussion as well as the support they received from Prof. S. E. Morsi, Dean of UNARC.

\section{References}

[1] Shiroishi, Y., Nakata, A., Sawada, S., J. Phys. Soc. Japan 40 (1976) 911.

[2] Tomaszewski, P. E., Dietraszko, A., Phys. Status Solidi (a) 56 (1979) 467.

[3] Mashihama, H., Hasebe, K., Tanisaki, S., Shiroishi, Y., Swada, S., J. Phys. Soc. Japan 47 (1979) 1198.

[4] BresczWeski, T., Krajewski, T., Mroz, B., Ferroelectrics 33 (1981) 9.

[5] Kassem, M. E. M., Mroz, B., Acta Physica Polonica A 63 (1983) 449.
[6] Phillips, F. C., An introduction to crystallography (Longmann press, London) 1946, p. 128.

[7] Daniels, T., Thermal Analysis (Kogam Page Limited, London) 1973, p. 127.

[8] Mitsui, T., Tatsuzaki, I., Nakamura, E., An introduction to physics of Ferroelectrics (Gardon and Breach Science Publisher, London) 1976, p. 47. 